News analysis.

\section{USA: the battle for the bars}

There is a growing wave of public support for greater restrictions on smoking in public venues, but of all the different types, exceptions are often made for bars. The usual arguments against smoking bans-fears of decreased profits, the rights of proprietors to choose whether to permit smoking, the rights of individuals to smoke, for example-can be applied equally to bars as to restaurants. We believe other forces are at work.

Research from a variety of sources shows the tobacco industry has increased its use of bars and clubs as promotional venues (see Tobacco Control 2002;11:94-104). Smoking restrictions in these areas deprive cigarette makers of critical marketing tools in an era when they are blocked from using most forms of mass market advertising. There are economic incentives for bars and nightclubs, but not restaurants, to continue this relationship.

More importantly, the tobacco industry collaborates with the alternative press to reach young adults who frequent these establishments. It is recognised today that smoking restrictions encourage people to quit-or at least reduce cigarette consumption. As such, public health ordinances present a serious threat to the profit margins of tobacco companies, drinking establishments, and alternative publications.

Secret internal 1994 documents from RJ Reynolds (RJR) describe the industry's strategy to use alternative publications to manipulate the preferences and behaviour of American youth. This involves a new marketing ploy referred to as Trend Influence Marketing (TIM). TIM abandons standard advertising campaigns and jumps directly into the arena of trying to "become the trend-maker". RJR and Philip Morris utilise TIM to increase the popularity of Camel and Marlboro cigarettes, respectively.

All articles written by David Simpson unless otherwise attributed. Ideas and items for News Analysis should be sent to David Simpson at the address given on the inside front cover
The effectiveness of TIM is not in question, yet this new strategy speaks directly of the continued deception associated with the tobacco industry. We followed the development of TIM in Albuquerque, beginning with the recruitment of clandestine smoking "hipsters" who surreptitiously peddle tobacco products to unsuspecting young adults, and tracked weekly tobacco industry penetration into the market using a free alternative publication.

By the early 1990s tobacco industry executives were under intense pressure from anti-smoking advocacy groups. Education efforts had increased awareness among consumers about the illusions in traditional tobacco product advertising. Facing declining sales, the industry began looking for a new approach. TIM acknowledges: "Shoving products in the face of the consumer is no longer the successful way to infiltrate this market. Today's 'Generation $X^{\prime}$ consumer is most influenced by what he or she sees in the hands of friends, not by some stiff riding a horse in a magazine advertisement."

The key element of TIM is to conduct the aggressive promotion covertly. "The minute someone blatantly pushes 'trendy,' it's not. Trend Influence Marketing is underground. For this program to be executed properly, we as a marketing company will appear almost invisible. Nothing that takes place can appear sales-oriented and everything we do will be perceived as cool. The objective is to have 'hipsters' feel as though smoking Camel is their idea, that they started the trend."

In RJR internal papers, executives emphasised that to reach the hipsters we must "speak their language, dress their dress, and walk their walk". The original RJR strategy is entitled "Camel Club". KBA Lifestyle Marketing, which developed the programme, added: "We will be recruiting our field marketing staff from the 'inside': people who have worked in and around the nightclub/bar business and trendy community."

TIM efforts are reinforced by savvy, localised alternative media campaigns. RJR executives noted: “There are many local, national and international newspapers and magazines that hipsters

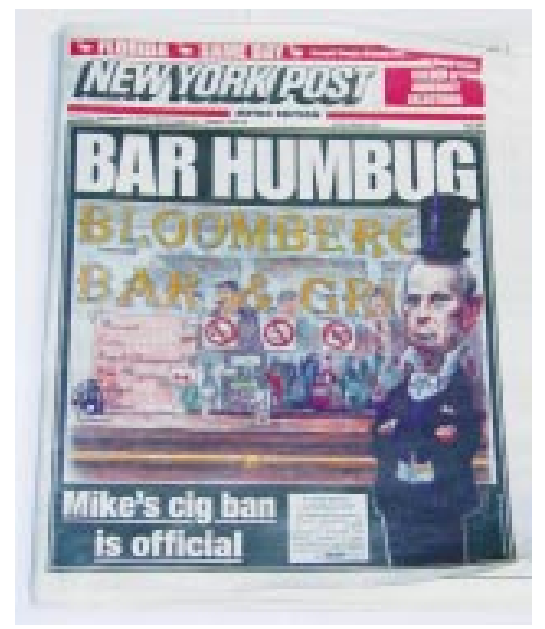

This front page comment from the Murdoch press in New York on Mayor Bloomberg's hard hitting ban on smoking in almost all public places speaks for itself.

read to follow the trends. These media vehicles are a critical part of the network to help the spread of trends ... These free periodicals are distributed at most trendy nightclubs and are found in the stores and coffeehouses that the club crowd frequents ... Aligning Camel with certain publications by way of advertising lends immediate hip credibility to the brand."

Most US cities have alternative publications. These tabloid-type newspapers are generally free to the public, widely distributed, and published on a weekly basis. Alternative publications are willing partners to this public deception. The Albuquerque publication runs a self promotion claiming their publication is "The Best Paper Money Can't Buy". Many young people under age 18 read the weekly editions, as the publication "targets every generation, from the Baby Busters to the Baby Boomers. Distributed throughout Albuquerque, Rio Rancho, Corrales, East Mountain, Bernalillo, Placitas, Santa $\mathrm{Fe}$ and Los Lunas". The publication is "available at restaurants, grocery stores, college campuses, select retailers and various downtown locations. Coverage includes politics, humor, film, opinion, music, art and the most comprehensive entertainment guide in Nuevo Mexico. Arriba!"

There are frequently numerous TIM advertisements per issue. The alternative publication has become the home 
base for modern tobacco marketing. Although the health community has succeeded in blocking Big Tobacco's encroachment into traditional markets, we are falling behind the collaborative efforts between the tobacco industry, bar and nightclub owners, and alternative press.

In the southwest, TIM promotion represents an aggressive form of tobacco marketing. The "iron triangle" formed by the tobacco industry, bar and nightclub lobby, and alternative press forms a powerful political opponent. We must recognise this new threat and confront the growing influence of this coalition in the political arena. The "Battle for Bars" symbolises more than private versus public intervention-it embodies the latest layer of tobacco industry deception where we must fight for the minds and health of America's young people. For a detailed review of TIM strategy, visit: http://www.tobaccofreedom.org/ issues/specials/alibi

SCOTT GOOLD Infolmagination, Albuquerque, New Mexico, USA; sgoold@infoimagination.org

\section{Fiji: finger for BAT}

Many readers will have been nauseated by reports generated from the publication of British American Tobacco's (BAT's) first "social report", part of its massive self rehabilitation exercise. Even the mere linking of a tobacco company's name to the concept of corporate social responsibility in a glossy document, while absurd to most people, seems enough to fool others into thinking it has changed its ways. On all the issues that really matter, BAT's social report is either cosmetic, evasive or deceitful, as Clive Bates of the UK's Action on Smoking and Health commented. "What is shocking is the gullibility of some parts of the ethical investment and corporate social responsibility community. They have blindly lapped up the glossy report and soothing PR without bothering to test if they are in any way related to BAT's real-world operations."

One truly emetic response appeared in the UK, BAT's home country, from the lofty sounding Institute of Business Ethics. An entire issue of its publication Ethical Performance was devoted to a company focus on BAT, most of it reading as if penned by the company's own PR staff. Page after designer polished page of lavishly illustrated articles, under headings such as Safer products, Supply chain monitoring, and Environment, prof- fered articles with equally positive and misleading titles-Playing it safe, Responsible production, and Greening tobacco, respectively.

How very reassuring, then, to find that in Fiji, a country so small that any big tobacco company might be tempted to think it could buy its respectability there with the greatest of ease, BAT got possibly the most robust and appropriate response of any in the world. Health minister Pita Nacuva cancelled a meeting with BAT officials, due to include nongovernment organisations and church representatives, accusing the company of unscrupulous advertising and promotional activities. "I would like to know whether this implies that selling death and diseases is legitimate," he mused, a tad rhetorically, one suspects.

BAT's local panjandrum described the cancellation as "disappointing" well, he would, wouldn't he? Congratulations minister; you are a model for public health colleagues worldwide.

\section{SIMPSON}

\section{Canada: demolishing the power walls}

Traditional forms of tobacco advertising are banned in Canada, and likely to stay that way after a landmark ruling last December from the Quebec Superior Court dismissing a constitutional challenge from the cigarette companies. However, extensive rows of cigarette packages, in quantities far greater than are necessary to supply consumers, are still a big part of the tobacco industry's marketing plan. Commonly called "power walls", these rows of tobacco products are found in stores across Canada and in many other countries. These displays are in clear view of children, placed next to confectionery, and reinforce the idea that smoking must be both very common and socially acceptable.

In June 2001, the province of Saskatchewan tabled legislation to ban tobacco product displays in public areas where young persons are permitted access.

A group proclaiming themselves to be "poor" retailers mounted an expensive campaign urging retailers to oppose the legislation. Not to be outdone, the provincial health coalition countered with an information and lobbying campaign of its own. The retailer group later admitted to being part of a tobacco industry coalition.

In July 2001 the Tobacco Control Act was unanimously passed by the provincial legislature and became law in March 2002. According to enforcement officers, implementation has gone smoothly. Compliance and acceptance are high and there have been no significant problems economically or otherwise. No tobacco products can now be publicly displayed at retail outlets in the province, thus ensuring that the availability of these products more adequately reflects their deadly nature.

In May, Rothmans Benson \& Hedges Inc, part of BAT, reacted to the loss of this last avenue to market to youth by launching a lawsuit. The province's minister of health, the Hon John Nilson, observed: "Our legislation

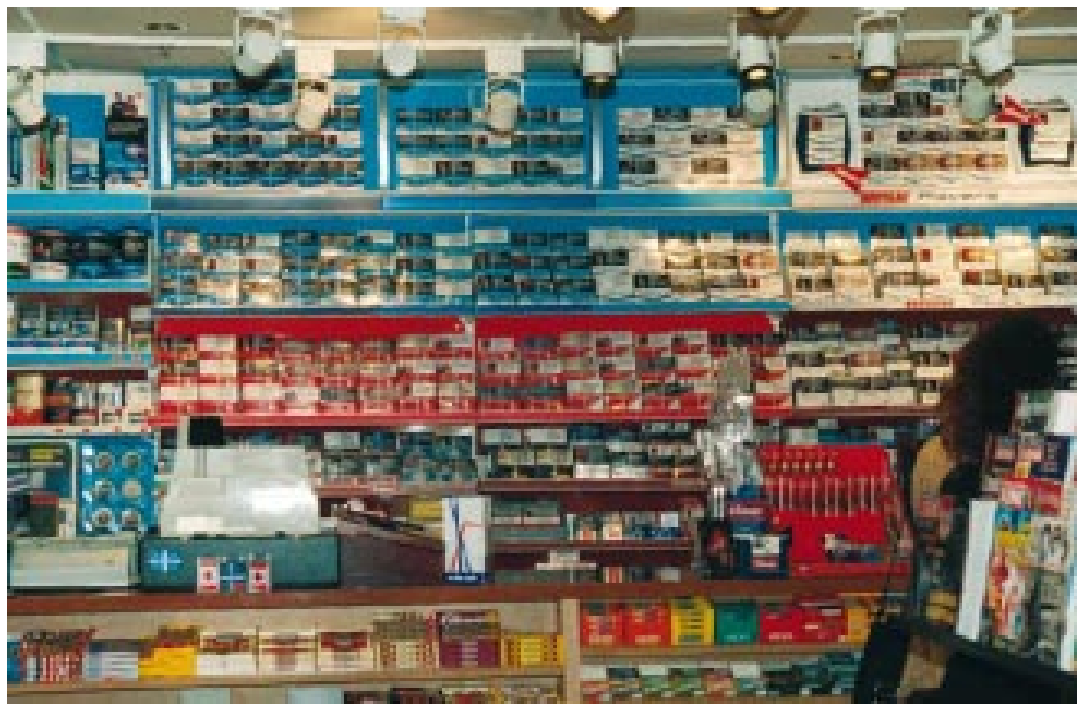

A "power wall" of tobacco products 


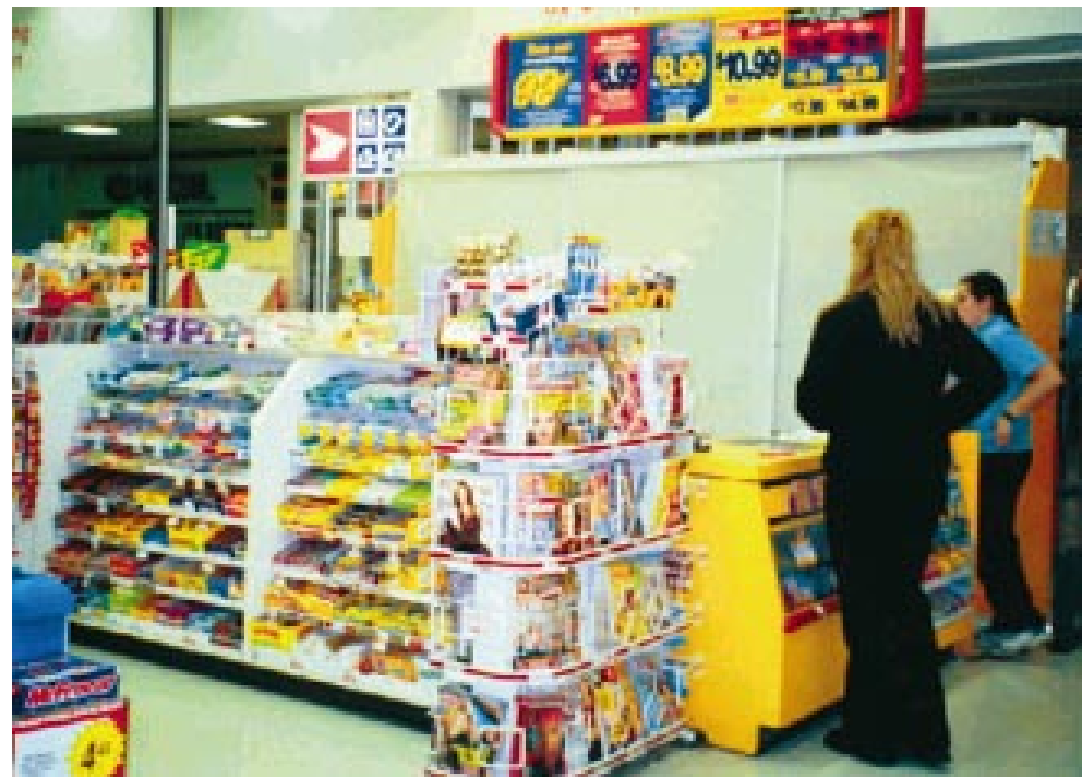

In this shop, a "power wall" has been replaced by closed cupboards.

must be working if this tobacco company is suing us ... The Government of Saskatchewan will defend The Tobacco Control Act from this attack. We will continue to prevent tobacco companies from displaying tobacco products that encourage people, especially youth, to smoke." The legal challenge was dismissed in September, but application to appeal was granted the following month. As with other measures aimed at reducing smoking, the tobacco companies never give up the fight. Nor, given the health issues involved, will Saskatchewan.

The banning of tobacco product displays is a new wave in tobacco control. Similar legislation has been passed in Iceland, Ireland, the Canadian province of Manitoba, and is being considered by other Canadian provinces and Australian states.

LYNN GREAVES Saskatchewan Coalition for Tobacco Reduction, Canada lynn.greaves@rqhealth.co

\section{Thailand: victories and defeats in the long war}

November 8 is a date of special significance in Thailand, as it is both the date of official funding of ThaiHealth in 2001 and the effective date in 2002 of new restrictions banning smoking in public places, including air conditioned restaurants. A previous article has highlighted that the adoption of the health promotion fund is a crucial milestone for tobacco control (Tobacco
Control 2001;10:48-54). While a quick survey shows tremendous strides for tobacco control, the tobacco industry has quietly gained ground in many areas, too. Thailand's efforts to monitor tobacco control indicators, gained policymaking friends and slowed or disabled important tobacco consumer protection efforts. For example, the ingredient disclosure requirements did not result in direct consumer disclosure of ingredients. While the pictorial health warnings on cigarette packs are approved and will eventually be in place, processes like this are often unnecessarily delayed. Tobacco industry documents from court actions make it clear that the transnational tobacco companies working in Thailand have been able to gain many allies among politicians, circumvent or flagrantly violate advertising laws, and influence the nature and extent of research on tobacco, by providing money or support to major research institutes and influential academics in Thailand. These three strategies, together with corporate sponsorship and philanthropy, have slowed progress in tobacco control.

A recent newspaper editorial in support of tobacco control in Thailand challenged tobacco control agencies to do more to achieve a rapid decline in the total number of smokers. Tobacco control advocates and organisations are seriously pursuing these end points as well as intermediate goals. Nonetheless, building an infrastructure of positive tobacco control programmes takes some time. It requires
The industry has been able to limit

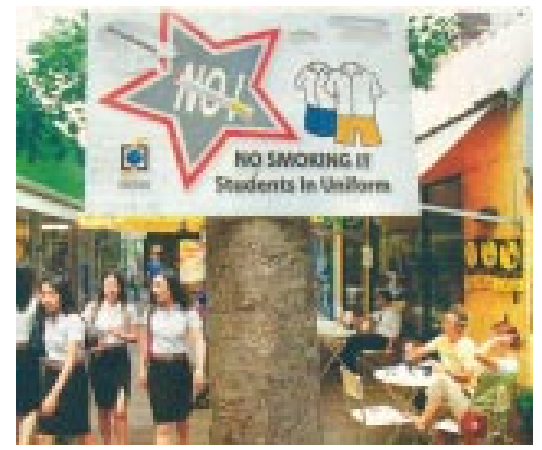

Students in Thailand pass a no smoking sign.

breaking down the industry's negative, well funded strategies of negligence, diversion, and delay. In short, the task is confronting and taking apart a complex hidden agenda supported by vast resources. So far so good, but the race is increasingly a case of constantly having to win the next victory, whether on November 8 or other dates each year, despite a continuous stream of obstacles from the tobacco industry.

STEPHEN HAMAN Rangsit University, Bangkok, Thailand; phncr@mahidol.ac.th

\section{Japan: smoke clouds over the land of the rising sun}

To western observers interested in tobacco control policy, Japan is a fascinating anomaly. Despite its extraordinary achievements in manufacturing and technology, coupled with its high levels of education and research, and an economy that until a recent blip, probably only temporary, has been a world leader, its smoking rates have been sky high, with subsequent disease levels to match. In many ways, to a westerner it is rather like a Germany of the East.

Two decades ago, Japan had the highest male smoking prevalence of any industrialised country, at around $80 \%$, but an almost negligible prevalence among women. Then came the invasion of American tobacco companies led by the US Trade Representative in 1985. Along with Thailand, Taiwan, and South Korea, Japan rolled over and modern tobacco promotion began. Until then, the Japanese tobacco monopoly (ironically, in view of Japan's high incidence of hypertension and stroke, it was called the Japan Tobacco and Salt Public Corporation) had been supplying a large and eager male market but had desisted from what must have so attracted the 
foreign invaders-the almost totally non-smoking female half of the population. A wind of change was in any case blowing through Japanese society, with increasing numbers of young women not only having significant disposable incomes-it is still quite common for young working women to live with their parents until marriage, usually later than their western counterparts-but traditionally strict attitudes to women's behaviour were softening. What better way for tobacco companies to recruit them than by somehow exploiting this new mood of liberation? Just as in many emerging, fast growing developing countries, the potential to nearly double the market by recruiting women to smoking must have been the western tobacco companies' dream come true.

Within a decade, smoking rates among young Japanese women had shot up, well on the way to those of young western women. Then, in 1999, Japan Tobacco (JT), as it was now called, bought the non-US business of RJ Reynolds. This catapulted the company, still two thirds owned by the state, into the same league as the newly merged BAT and Rothmans, making it second equal in size after Philip Morris. Added to the existing high smoking rates-though men were beginning to quit-the potential for serious tobacco control was dealt a severe blow, as the government was now swung sharply to the side of tobacco.

Japan therefore suffers more than its fair share of that unsatisfactory dichotomy common to many governments, whereby the ministry of finance, unaware or unconvinced that tobacco tax rises can increase revenue while lowering consumption, is by far the most powerful ministry, and resists any policy that might reduce consumption. In fact, whatever the finance ministry might want to do, as majority owner of JT it is legally bound to defend its huge investment. Conversely the ministry of health, always low in any country's cabinet pecking order, became relatively lower still, condemned to a weary cycle of trying to develop policies that might actually reduce future disease levels, then watering them down progressively as the ministry of finance, no doubt advised by its charges at JT, ensures that nothing that could seriously affect it is ever implemented. Most official health initiatives, despite some valiant attempts, end up with a noticeably soft "advisory" flavour. The only hope of health prevailing over tobacco is when the government sells its majority shareholding in $\mathrm{JT}$, something it is pledged to do but has put off until the share price, hit by the recent recession, makes a significant recovery.

Advertising and promotion has continued to flourish. From the early onslaught by Philip Morris, including its notorious exploitation of the 1980s Japanese cult for James Bond movies, in which the company's Lark brand was contracted into a movie playing to sell-out young audiences, tobacco promotion has steadily developed, nowadays with full participation by JT, into something much more recognisable to western eyes. Uncannily familiar, in fact-due to Japan's unique, strong cultural traditions, ads for products that may be seen as controversial or embarrassing tend to use western models. For example, billboard ads for women's underwear, a fairly essential commodity in Japan as elsewhere, show western women rather than their Japanese sisters. Tobacco ads targeted to women follow the same line-about the only sign of any reservation by society about the plethora of seductive ads clearly designed to appeal to girls and young women.

Other forms of promotions to women are more subtle, if more devious. Last year, Salem ran a promotional package of two packs of Salem cigarettes, an unmistakably girlie, pocket sized pink powder compact, and a booklet of special offers. It showed a wide range of household goods, of typically fine and attractive Japanese design, available to those young women lucky enough to buy the pack. Not surprisingly, some of the same young schoolgirls who can be seen experimenting with make-up as they dawdle back home after school can now be seen smoking in the street, too.

Perhaps the greatest give-away of the government's enslavement to to-

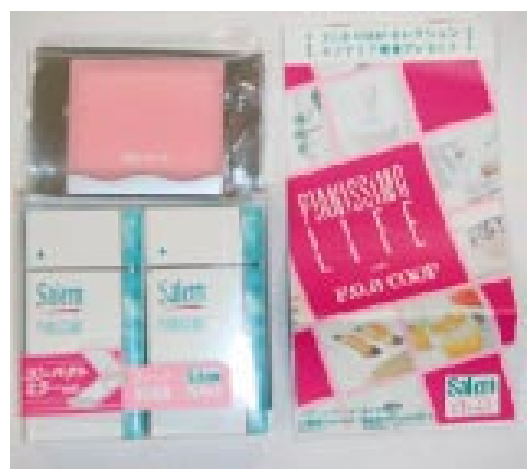

Salem special offer pack targetted at the young female market in Japan, containing two packs of cigarettes, a powder compact and a booklet of special offers.

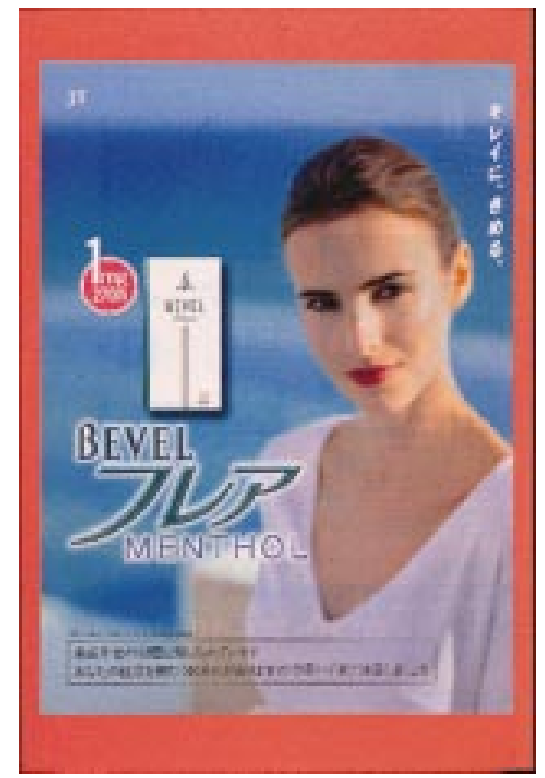

A Japanese advertisement for the Bevel brand of cigarettes, using a western model

bacco is its approach to the Framework Convention on Tobacco Control. The ministry representing Japan in the negotiations has been the ministry of finance-the health ministry had mere observer status on a committee assembled to inform the government's negotiating position. True, one member of the committee was a scientist, but he had a track record of research on addiction for JT. The chairman himself was a cardiologist, with no known tobacco connection, but unfortunately, Japanese tradition demands that the independence of the chair is observed scrupulously, so that those chairing committees cannot make known their views. Other committee members included a stockbroker, representatives of tobacco retailers and farmers, and a steel company executive.

Whatever some officials in the health ministry might wish to do, then, taking a strong lead in tobacco control is simply not possible while the government remains the majority shareholder in JT. Non-governmental organisations (NGOs), however, are becoming more active. Japan has always had some active NGOs working on tobacco, as well as a number of individual activists, but while the larger medical charities have tended in the past to stick to safer topics such as cessation and youth education programmes, recent years have seen signs of change. The Japan Cancer Society, for example, which in the past mainly concerned itself with screening, is now moving towards primary prevention. Half a dozen organisations, including 
cancer and heart charities, foundations for maternal and child health, and the anti-tuberculosis association, have been working together within an NGO council for tobacco control.

More recently, the Japan Medical Association (JMA) and the Japan Nursing Association have both become much more active on tobacco. Last year, for example, the JMA translated Doctors and tobacco, the action guide for medical associations and their members, and used it to hold well attended seminars in several population centres, including one at the headquarters of the JMA in Tokyo. It was encouraging to find that much progress has been made in recent years by modest yet highly active leaders in the national and regional medical associations. They have surveyed doctors' smoking rates and attitudes, as well as making medical association premises smokefree. Doctors' smoking rates, while high for such an advanced society, are now coming down (from a 1999 level of around $27 \%$ for men, $7 \%$ for women), and there is increasing interest in tobacco control.

Japan has about 260000 doctors, of whom around $60 \%$ belong to the JMA. Public health, one of the natural pools of leadership on tobacco control found in other countries, has almost no system for qualification in Japan, even though it is a recognised medical specialty. So far there is only one school of public health, part of Kyoto University, which opened two years ago. There is a growing demand to get smoking cessation counselling included among services for which doctors are reimbursed, with all the related problems of quality control and assurance of the delivery of an effective service. As in other countries, many clinicians routinely try to get their patients to quit, and some feel that their colleagues should do the same whether or not they are reimbursed. Meanwhile, in the business world, employers are increasingly realising the benefits of getting smoking employees to quit, and making workplaces smoke-free.

In Japan's often smoky public places, too, there is progress, even if the most publicised smoking ban recently, on certain busy Tokyo streets, was motivated by people, especially children, being burned by the glowing cigarette butts of careless smokers rushing by. Seeing that the epidemiology of passive smoking and lung cancer began life in Japan, with the late Professor Takeshi Hirayama's 1981 pioneering study, a more sustained,

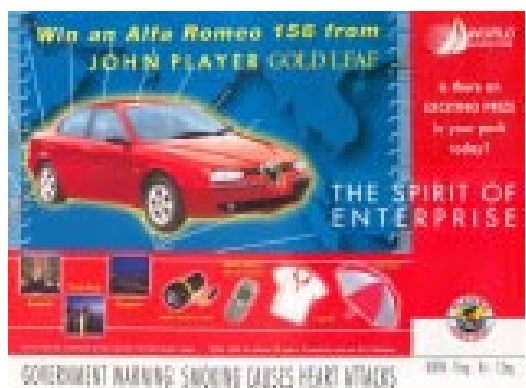

Sri Lanka: With another tobacco promotion where luxurious prizes beyond the dreams of most ordinary people are offered to smokers, BAT clocks up a new Hall of Shame entry in Sri Lanka, where this John Player Gold Leaf in-pack prize scheme to win an Alfa-Romeo car was running at the end of last year.

science based public places campaign might have been expected. However, the politeness for which Japan is so deservedly famous is, for tobacco control, a two edge sword. On the one hand, it means that when there are no smoking areas, in public transport and certain other (though too few) public places, they tend to be scrupulously observed; on the other hand, in terms of ordinary members of the public asserting their right to breathe smokefree air, Japanese people must be among the most reticent in the world, at the opposite end of the spectrum from the non-smokers of the USA whose constant and assertive demands have proved so potent.

There are signs that coalitions of anti-smoking groups will coalesce into a more powerful force, and there is a growing demand for training. There is likely to be a record Japanese contingent in Helsinki this summer. We must hope that Japan's economy allows the government to sell its JT shares, and begin the serious business of handson, health driven, comprehensive tobacco control.

D SIMPSON

\section{Where are they now?}

What happens to scientists and others revealed by tobacco industry documents to have been agents for the brown army? Readers are invited to submit their modern day discoveries of those names familiar to us from the tobacco papers. Meanwhile, here's one to ponder. At a conference last December to mark the 50th anniversary of the great London smog, two figures were seen huddled together, apparently reluctant to socialise with the more than 200 other delegates present, mainly physicians and scientists. The two turned out to be George Leslie, heavily involved in organising industry sponsored conferences on indoor air quality, including some in the Far East; and John Hoskins who edited Indoor Air International (now Indoor+Built Environment of the International Society of the Built Environment) in the days when seemingly all the board were industry funded. Will they now be penning papers to show that pollution levels in cities such as London are really the cause of much of the disease blamed on smoking? Watch this space.

D SIMPSON

\section{Hong Kong, China: return of the butt people}

There's something rotten in the Special Administrative Region. Having progressed from almost zero tobacco control 20 years ago to being a regional leader with a comprehensive tobacco control policy by the time it was handed back to China in 1997, Hong Kong is beginning to look decidedly vulnerable to the ever present threat of attack by the tobacco industry. Most sinister is the frequent appearance of people infamous for their previous service to the industry, in new appointments not just in government, but in the health sector.

For example, the University of Hong Kong's medical faculty, whose department of community medicine is a world leader in research on the effects of smoking on health, has accepted free public relations services from Brenda Chow, the former Tobacco Institute chairwoman and local public affairs director of BAT. The dean of the medical faculty, Professor Lam Shiukum, told staff in a memo that the university had invited her to organise a series of media workshops, describing Ms Chow as a "renowned and experienced PR consultant", but failing to mention her tobacco industry background.

And he certainly made no mention of her being not so much renowned, but notorious in the eyes of most public health professionals, for a long history of the very worst sort of industryspeak in the mass media. "Smoking may be a risk factor [for cancer], but that doesn't mean cause," she said in 1989. “There's no point in carrying on [with health warnings] when people know about it." She did not neglect the more traditional industry mantras, 
such as "Advertising is not a significant factor in encouraging youngsters to begin smoking". In 1992, she eulogised about colourful tobacco ads making Kai Tak airport the jewel it then was " . . .essential ingredients in the local landscape". In 1997, she greeted the total tobacco ad ban in the final round of legislation of the colonial government as " . . five steps backwards". By 2001 she was on to addiction: "If nicotine is so addictive, how come the nicotine patches do not sell? Tobacco is an easy target. People jump on the bandwagon." She also opposed rises in tobacco duty and government funding for the Council on Smoking and Health ( $\mathrm{COSH})$. In short, she seems to be the sort of person who, on the face of it, would be about as welcome in a medical faculty as the proverbial rattlesnake in a lucky dip.

Some months earlier, the government appointed Sarah Liao Sau-tung as secretary for environment, transport and works. She had been a Philip Morris consultant on passive smoking, receiving an estimated $\mathrm{HK} \$ 1$ million (US\$128 000) in 1990 from the largely tobacco funded Centre for Indoor Air Research to study air quality in Hong Kong. Her co-researcher, John BaconShone, has also been named as a tobacco consultant. Both deny knowing that the tobacco industry was the source of the funding, but an industry lawyer said he told Ms Liao. Perhaps she forgot.

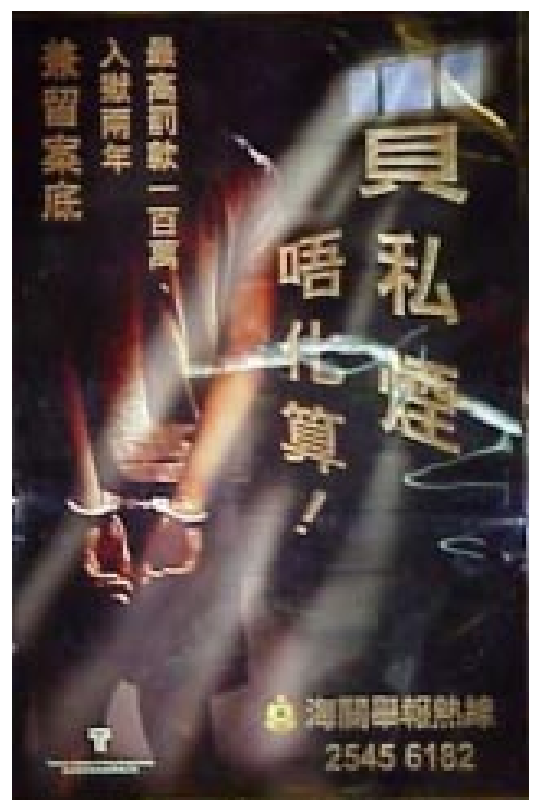

Customs and Excise advertisement in Hong Kong, indicating the dire consequences for anyone caught smuggling cigarettes, which is jointly supported by the Tobacco Institute (whose logo appears in the bottom left corner of the poster).

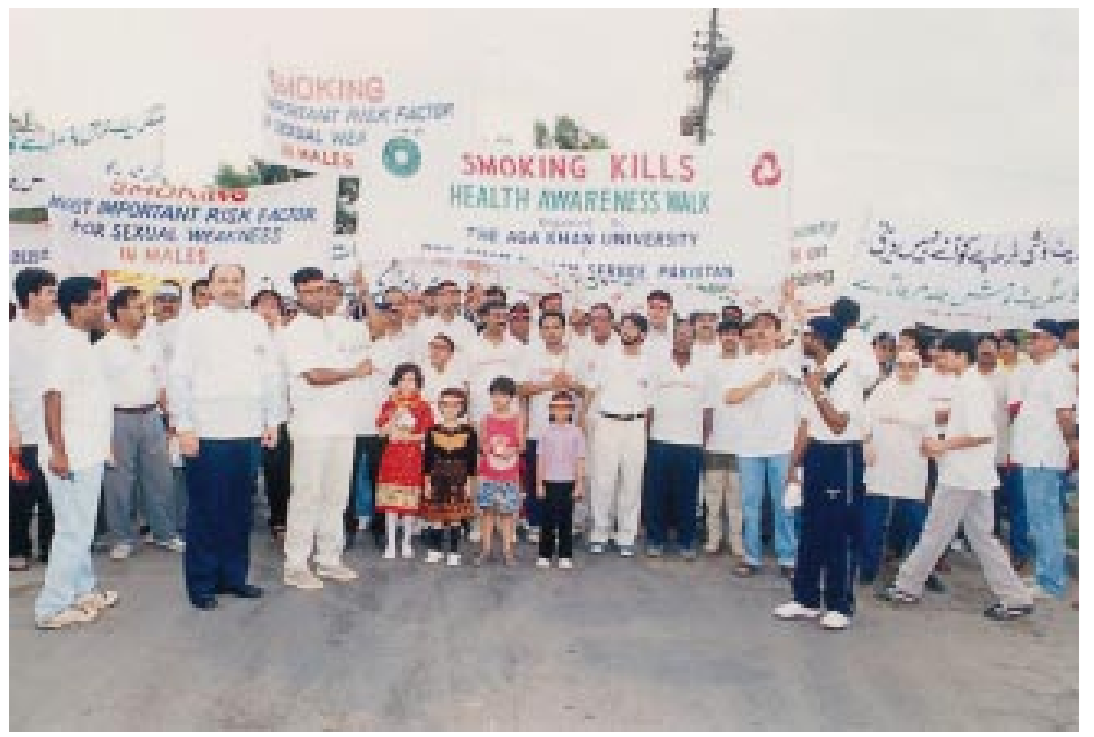

In Pakistan, the Agha Khan university in Karachi has been playing an important role in educating society about tobacco, in this case, by organising a well attended march, complete with thought provoking posters for World No Tobacco Day last May.

Then there is the case of Mr Lee JarkPui. He served as executive director of the Hong Kong Tobacco Institute for seven years until 1994, but is currently a member of the Hospital Authority Board, on which also sits Professor Lam Shiu-kum. Aside from this apparently careless lack of discrimination in public sector appointments, a succession of attempts by tobacco companies to fund educational programmes of the "We've changed!" variety have been rumbled and in some cases prevented. But tobacco is a many headed Hydra and no doubt other schemes get through, big and small, before anyone realises their provenance.

An unexpected and singularly inappropriate alliance between tobacco and the government popped up last November, when health advocates were appalled to see advertisements by the Customs and Excise department urging the public not to smoke contraband cigarettes and to shop anyone they thought was involved in smuggling. Not surprisingly, COSH fired off a letter citing a review of over 160 reports from the media, governmental and other sources worldwide on the issue of tobacco industry involvement in smuggling. It added a clear reminder that if an ongoing investigation resulted in prosecution of tobacco industry players, there would be severe embarrassment for the Hong Kong government arising from this unhealthy new alliance.

Astonishingly, the response from the Customs and Excise department, signed by one K Chow (presumably no relation), was written in terms that might have been drafted by Brenda
Chow herself. "Smoking is a complex social phenomenon," it began. "It is the government policy to introduce tobacco control measures in a step-bystep approach ..." and after a few more sentences of child level explanation of government policy, and reiteration of the department's commitment to educate the public not to buy illicit tobacco, it ended: "We appreciate the perception problem you raised and wish to assure you that we will take that into account when planning our future educational efforts." Perception problem? Is this a new style euphemism from the industry stable? With government departments like this, what need has the industry of friends?

D SIMPSON

\section{Doctors' manifesto}

In 1951, British researchers Richard Doll and Austin Bradford Hill began a study that provided convincing evidence that the great majority of lung cancers were caused by smoking. The subjects of their study were some 40000 British doctors. Now, 50 years after that study, there is another historic opportunity for doctors to make use of their unique position.

In the British Medical Association publication Tobacco under the microscope, doctors examine the evidence, identify best practice, and set out their manifesto for global tobacco control. Some 30 eminent doctors from around the world contributed to the manifesto, and umbrella medical associations whose member organisations represent more than 10 million doctors in 


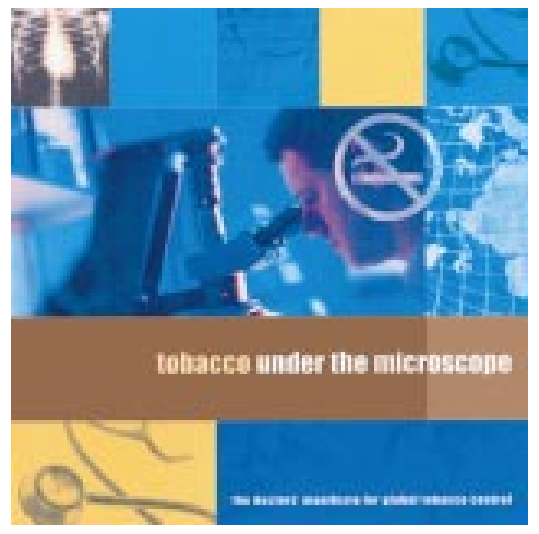

117 countries have pledged their support to it. Based on the evidence, it focuses on the five measures that have proved most effective in the battle to curb deaths from smoking, and which doctors would like to see included in the convention: clear and informative pack health warnings; an end to

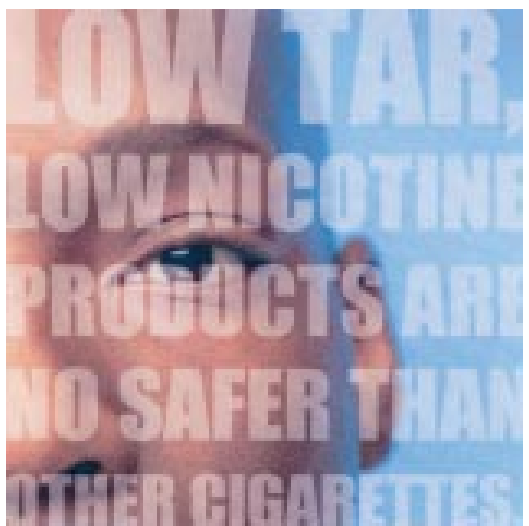

misleading claims that some cigarettes are safer than others; increases in the price of tobacco through taxation; the protection of non-smokers from tobacco smoke; and an end to all forms of tobacco advertising.

Speaking at the launch of the manifesto, Dr Gro Harlem Brundtland, director general of the World Health Organization, reiterated the important role of doctors in tobacco control. "Behind this manifesto lies an enormous amount of evidence, of science and of the personal experience of millions of doctors who have watched their patients get ill and die from their tobacco addiction. When a physician speaks, most people take notice. So should policymakers."

By visiting the manifesto website (www.doctorsmanifesto.org) doctors and medical associations can sign up to the manifesto and contribute a statement to the web based document. In addition, online postcards can be sent on the key issues of tobacco control.

HELEN FREW

SINÉAD JONES

Tobacco Control Resource Centre, UK; sjones@bma.org.uk

\section{The lighter side}

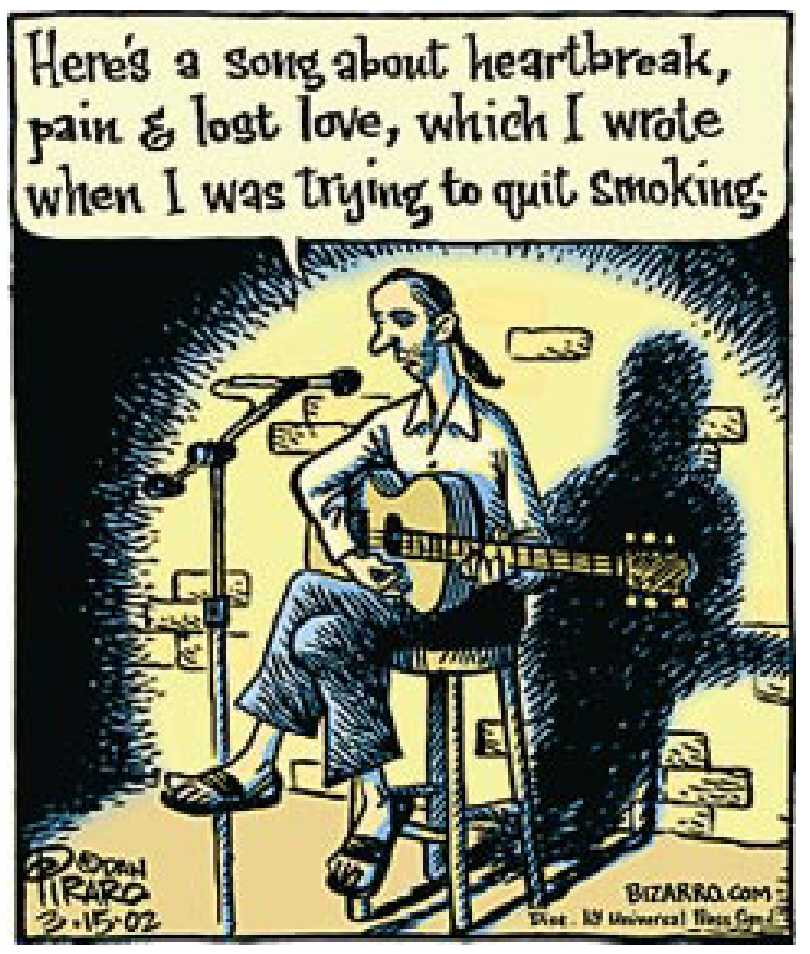

(c) Bizzaro by Dan Piraro. UComics. Friday, March 152002. 